\title{
A dual electro-optical biosensor based on Chlamydomonas reinhardtii immobilised on paper- based nanomodified screen-printed electrodes for herbicide monitoring
}

\section{Amina Antonacci}

Institute of Crystallography National Research Council: Istituto di Cristallografia Consiglio Nazionale delle Ricerche

\section{Raouia Attaallah}

University Hassan II Casablanca: Universite Hassan II Casablanca

\section{Fabiana Arduini}

University of Rome Tor Vergata: Universita degli Studi di Roma Tor Vergata

\section{Aziz Amine}

University Hassan II Casablanca: Universite Hassan II Casablanca

\section{Maria Teresa Giardi}

Institute of Crystallography National Research Council: Istituto di Cristallografia Consiglio Nazionale delle Ricerche

Viviana Scognamiglio ( $\nabla$ viviana.scognamiglio@ic.cnr.it )

Institute of Crystallography National Research Council https://orcid.org/0000-0002-4932-8491

\section{Research}

Keywords: electro-optical transduction, screen-printed electrodes, paper-based biosensors, GRAS organisms, eco-friendly

Posted Date: March 31st, 2021

DOI: https://doi.org/10.21203/rs.3.rs-369389/v1

License: (c) (1) This work is licensed under a Creative Commons Attribution 4.0 International License. Read Full License 


\section{Abstract}

The indiscriminate use of herbicides in agriculture contributes to soil and water pollution, with important endangering consequences on the ecosystems. Among the available analytical systems, algal biosensors have demonstrated to be valid tools thanks to their high sensitivity, cost-effectiveness, and eco-design. Herein, we report the development of a dual electro-optical biosensor for herbicide monitoring, based on Chlamydomonas reinhardtii whole cells immobilised on paper-based screen-printed electrodes modified with carbon black nanomaterials. To this aim, a systematic study was performed for the selection and characterisation of a collection among 28 different genetic variants of the alga with difference response behaviour towards diverse herbicide classes. Thus, $\mathrm{C} 125$ strain was exploited as case study for the study of the analytical parameters. The biosensor was tested in standard solutions and real samples, providing high sensitivity (detection limit in the pico/nanomolar), high repeatability (RSD of $5 \%$ with $n=$ 100), long lasting working (10 h) and storage stability (3 weeks), any interference in the presence of heavy metals and insecticides, and low matrix effect in drinking water and moderate effect in surface one.

\section{Introduction}

In the last decades, pollution of soil and water from toxic chemicals as pesticides caused general concerns for the resulting harmful effects on the ecosystems and human health. Approximately, 2 million tonnes of pesticides are annually exploited worldwide with a total sale over the period 2011-2018 of around 360.000 tonnes per year in the EU. The major pesticide groups which recorded the highest sales volumes have been "fungicides and bactericides" and "herbicides, haulm destructors and moss killers" (Eurostat report, 2020). In particular, herbicides belonging to the triazine and ureic classes are largely exploited in agriculture to remove grasses and weeds for enhancing crop yield and thus ensuring global food security. Although their usage is beneficial for crop production, extensive use of herbicides causes important detriment on animals and ecosystems, due to their bio-magnification and persistent nature. This urgent issue struggled the development of new technologies, in support of the conventional ones, for the monitoring of these compounds in the environment. The last trends on the design of high-throughput platforms exploiting algae seems to be a versatile solution for the fabrication of biosensors (Antonacci \& Scognamiglio, 2019). Indeed, these photosynthetic microorganisms are very sensitive to specific environmental changes, enabling the detection of ultra-traces of pollutants. In particular, algae-based biosensors represent intriguing devices for photosynthetic herbicide detection (triazine and ureic classes). Their mechanism of action is strictly related to the fluorescence of the chlorophyll $a$, and its modulations in presents of xenobiotic compounds. The strong potential of algae-based biosensors relies on reliable monitoring of these intracellular variations in real time and in situ, basically by two main transduction methods, i) optical (i.e. fluorescence induction curves) and ii) electrochemical (i.e. amperometry), both in a herbicide concentration-dependent manner (Antonacci \& Scognamiglio, 2019). The use of algae as biorecognition element tightly fits with biosensor requirements, in particular concerning the sensitivity 
able to meet the MRL of EU Directives for drinking and surface waters (EU Directive 98/83/EC; EU Dir. 2013/39/EC).

Several promising studies from the scientific literature highlight the appealing and versatile technology of algae-based biosensors, thanks to many advantages, including very high sensitivity in the pico/nanomolar range, fast analysis ( $15 \mathrm{~min}$ ), high operational stability (10-12 hours), medium storage stability ( 3 weeks at room temperature under light), high repeatability, optimal conjunction of algae with nanomaterials e.g. carbon black nanoparticles and smart materials e.g. paper substrate, simple integration into portable sensing prototypes also in dual transduction system i.e. optical and electrochemical, the availability of interchangeable bioreceptors (able to recognise many toxic chemicals as herbicides and chemical weapons), reversible mechanisms of herbicide detection (repeated analysis of the target through washes with buffer), and no need for sample pre-treatment (Attaallah et al., 2019; Scognamiglio et al., 2019; Giardi et al., 2013; Elisabeth et al., 1987).

Many biosensors reported in literature, using photosynthetic recognition elements, specifically exploit the inhibition of PSII photochemical reaction in the presence of different toxic compounds. Several studies report the design of optical and electrochemical biosensors exploiting both whole microalgae cells and their sub-components as thylakoidal membrane and extracted PSII or reaction centres. Nevertheless, these analytical systems suffer from some drawbacks which hinder their practical use in-the-field, as low selectivity as well as low yield of algae immobilisation protocol, which results in a low repeatability in the preparation of algae-based sensors (Antonacci \& Scognamiglio, 2019). With the intent to contribute in coping with these main drawbacks, we propose an efficient approach to test whole cells of $C$. reinhardtii as a good biocomponent, for the development of an eco-designed dual transduction algal biosensor for herbicides detection, exploiting the green photosynthetic alga Chlamydomonas reinhardtii immobilised on paper-based screen-printed electrodes modified with carbon black nanomaterials (pCB-SPEs). The novelty of this study relies on $\mathrm{i}$ ) the systematic study of a huge collection of $C$. reinhardtii genetic variants, performed for the first time to widen the availability of smart bioreceptors for herbicide detection among different classes from triazine to ureas; ii) the immobilisation of algae whole cells on nanomodified electrodes scree-printed on paper as substrate. This choice also encompasses the fundamentals of sustainability of the 2030 Agenda for Sustainable Development (Agenda Item, 2019; Bartolucci et al., 2020; Arduini et al., 2020), because of the eco-friendly nature of both paper substrate and the algae, recognised by the Food and Drug Administration (FDA) as a Generally Recognized as Safe (GRAS) organism (Sections 201/409 FDA).

\section{Materials And Methods}

\subsection{Growth conditions of the algal liquid cultures}

All the strains of $C$. reinhardtii were maintained under continuous light $\left(50 \mu \mathrm{mol}\right.$ photons $\left.\mathrm{m}^{-2} \mathrm{~s}^{-1}\right)$, at $25^{\circ} \mathrm{C}$, and on tris-acetate-phosphate (TAP) agar culture medium plates. Prior to each experiment, each strain was collected with a sterile loop and used to inoculate stock culture made in $100 \mathrm{~mL}$ flasks with $50 \mathrm{~mL}$ of 
liquid TAP closed with bacteriological cotton. Flasks were placed into an orbital shaker at $25^{\circ} \mathrm{C}$, stirring at $150 \mathrm{rpm}$ and under continuous light $\left(50 \mu \mathrm{mol}\right.$ photons $\left.\mathrm{m}^{-2} \mathrm{~s}^{-1}\right)$. All the materials and media used for the inoculation were sterilized in the autoclave at $120^{\circ} \mathrm{C}$ and 1 bar pressure for 20 minutes. The inoculation was performed under the biological fume hoods to avoid any contamination.

After 72 hours from inoculation the optical density of each strain culture was checked by spectrophotometer analysis at a $750 \mathrm{~nm}$ wavelength in TAP medium. After this measurement, the algae cultures were diluted in TAP to an optical density of $0.15 \mathrm{OD}_{750}$ in a final volume of $200 \mathrm{~mL}$. Then the refreshed cultures were mixed on an orbital shaker under the same conditions above reported for all the period of the physiological characterisation.

\subsection{Algae physiological characterization}

All experiments were performed under continuous light $\left(50 \mu \mathrm{mol}\right.$ photons $\left.\mathrm{m}^{-2} \mathrm{~s}^{-1}\right)$ and agitation (150 rpm) at $25^{\circ} \mathrm{C}$, starting with cell cultures in early mid-exponential growth phase, with $\mathrm{Abs}_{750}$ 0.5 O.D., $10^{6}$ cells $/ \mathrm{mL}$, and $5 \mu \mathrm{g} / \mathrm{mL}$ chlorophyll content. Cell culture growth was spectrophotometrically evaluated measuring the absorbance (O.D.) at $750 \mathrm{~nm}$ wavelength. Cell number was quantified using a Bio-Rad TC10 automated counter (Hemel Hempstead, UK), using a $10 \mu \mathrm{L}$-volume cell counting slide. Pigment content was spectrophotometrically measured by quantifying the absorbance (O.D.) of the chlorophylls $a$ and $b$ at $652 \mathrm{~nm}$ wavelength, once extracted with $80 \%$ acetone. Chlorophyll extraction: $1 \mathrm{~mL}$ of cell culture was harvested and centrifuged at $13000 \mathrm{rpm}$ for $5 \mathrm{~min}$ to destroy all the phospholipidic membranes and preserve the pigments. $800 \mu \mathrm{L}$ of the supernatant was removed and the remaining pellet and $200 \mu \mathrm{L}$ supernatant was diluted by adding $800 \mu \mathrm{L}$ of $100 \%$ aqueous acetone. The solution is vortexed for 2 minutes in dark and then centrifuged for 3 minutes. The total of chlorophyll content was determined spectrophotometrically measuring the absorbance at $652 \mathrm{~nm}$ ( $80 \%$ acetone is used as blank). The calculation of the total chlorophyll concentration expressed as $\mu \mathrm{g} / \mathrm{mL}$ was performed by the equation: $($ O.D. $652 \times 1000) / 34.5$. The photosynthetic profile was assessed by the chlorophyll a fluorescence induction (Kautsky) curves, recorded with a Plant Efficiency Analyzer (PEA) at room temperature after 10 min of dark adaptation and with a $5 \mathrm{~s}$ saturating pulse excitation light $\left(3500 \mu \mathrm{mol}\right.$ photons $\left.\mathrm{m}^{-2} \mathrm{~s}^{-1}\right)$ using an array of six red light emitting diodes (650 nm peak). The measurement was carried out in a small flask containing $5 \mathrm{~mL}$ culture in two steps: i) in the dark to ensures the removal of energy motor of photosynthesis (photons) and discharge the photosynthetic chain from electrons; then the reaction centres are all ready for the acceptance of new electrons and the photosynthetic machinery is actually in a basal state of zero fluorescence $\left(\mathrm{F}_{0}\right)$; ii) under light to provide saturating light flash, thus inducing a reduction of all reaction centres $\left(Q_{A}\right)$ and obtaining a maximum fluorescence value $\left(F_{M}\right)$. The excess of light energy, uncollected by PSII, takes different paths, including heat dissipation and fluorescence emission, according to a particular kinetics; then the electron transfer chain is switched on and reaches a steady state. 
Kautsky curves or OJIP curves are defined by a polyphasic fluorescence rise in the time, with $\mathrm{O}$ as the minimal dark- acclimated fluorescence level (indicating that all $Q_{A}$ are oxidised) and $P$ as the maximal level (indicating that all PSII quinone acceptors are fully reduced). The difference in the fluorescence signal of these distinct states helps evaluating the PSII functionality through the following parameters calculated by the fluorimeter:

- $F_{0}$ or fluorescence in initial state: minimum fluorescence intensity in the state acclimated to the darkness, recorded when all PSII reaction centres are open (oxidized quinones).

- $F_{M}$ or maximum fluorescence: maximum fluorescence intensity reached after 10 minutes of darkness and a subsequent saturating light pulse, recorded when all reaction centres of the PSIl are closed (reduced).

- $\mathrm{F}_{\mathrm{V}} / \mathrm{F}_{\mathrm{M}}$ : maximum fluorescence yield of PSII photochemical reaction expressed as ratio of variable fluorescence $\left(\mathrm{F}_{\mathrm{M}}-\mathrm{F}_{0}\right)$ and maximum fluorescence, calculated according to the equation:

$\mathrm{F}_{\mathrm{V}} / \mathrm{F}_{\mathrm{M}}=\left(\mathrm{F}_{\mathrm{M}^{-}} \mathrm{F}_{0}\right) / \mathrm{F}_{\mathrm{M}}$

where $F_{V}$ represents the maximum variable fluorescence calculated as $F_{M}-F_{0}, F_{M}$ corresponds to the maximum fluorescence emission and $F_{0}$ is the minimum fluorescence emission.

It reflects the efficiency of PSII in using light for photochemical conversion and its value is usually at 0.8 in physiological conditions or decreased values under stress.

Furthermore, $\mathrm{J}$ and $\mathrm{I}$ intermediate points represents a direct indication of transient changes in the plastoquinone redox state within the PSII reaction centre, as the accumulation of $\mathrm{Q}_{\mathrm{A}}$ in reduced state and the consequent filling up of the plastoquinone pool with electrons. Any change in the PSII electron transfer efficiency directly causes variations in the fluorescence intensity of the inflection points, as a consequence of different stress conditions. In particular, the variable fluorescence parameter $1-V_{J}$ provides a specific response directly related to the herbicide-D1 binding niche interaction, and it can be calculated according to the equation:

$1-V_{J}=1-\left(F_{2 m s}-F_{0}\right) /\left(F_{M}-F_{0}\right)$

where $F_{0}, F_{M}, F_{2 m s}$ are respectively the initial fluorescence, the maximum fluorescence and the fluorescence measured after 2 ms (Giardi et al. 2009).

\subsection{Algaeimmobilisation protocol}

C. reinhardtii cell cultures in early mid-exponential growth phase, with Abs 7500.7 0.D., $10^{7}$ cells $/ \mathrm{mL}$, and 10 $\mu \mathrm{g} / \mathrm{mL}$ chlorophyll content, were exploited for the immobilisation on paper-based screen-printed electrodes nanomodified with carbon black (pCB-SPEs). A volume of $14 \mathrm{~mL}$ of cell cultures were 
harvested by $10 \mathrm{~min}$ centrifugation at $2000 \times \mathrm{g}$ and $15^{\circ} \mathrm{C}$ to obtain a final amount of cells equal to 1.2 $\times 10^{7}$. The cell pellet was re-suspended in $50 \mu \mathrm{L}$ of $50 \mathrm{mM}$ tricine $\mathrm{pH}$ 7.2, and mixed with $100 \mu \mathrm{l}$ of a $1 \%$ $(\mathrm{w} / \mathrm{v})$ sodium alginate solution in the same buffer, obtaining a final cell concentration of $0.08 \times 10^{6}$ cells $/ \mathrm{mL}$. $5 \mu$ l of this suspension, containing $\sim 4 \times 10^{5}$ cells, were deposited over a carbon black nanomodified working electrode surface (diameter $3.0 \mathrm{~mm}$ ) of a three-electrodes system printed on paper, with a carbon and an $\mathrm{Ag} / \mathrm{AgCl}$ reference electrode. $5 \mu \mathrm{l}$ of $200 \mathrm{mM} \mathrm{CaCl}_{2}$ in $50 \mathrm{mM}$ Tricine- $\mathrm{NaOH}$ were drop cast on the deposited algae to allow the physical gelation of the alginate and the consequent entrapment of cells on the working electrode, keeping in mind that this step needs to be done more quickly to avoid damage to the algae cells due to running dry. Finally, algae/pCB-SPEs were stored into 50 $\mathrm{mM}$ Tricine, $20 \mathrm{mM} \mathrm{CaCl}_{2}, 5 \mathrm{mM} \mathrm{MgCl}_{2}, 50 \mathrm{mM} \mathrm{NaCl}, 70 \mathrm{mM}$ sucrose $\mathrm{pH} 7.2$ and incubated for $2 \mathrm{~h}$ under continuous light $\left(50 \mu \mathrm{mol}\right.$ photons $\left.\mathrm{m}^{-2} \mathrm{~s}^{-1}\right)$ and $25^{\circ} \mathrm{C}$.

\subsection{Herbicide analysis}

The optical and electrochemical analysis of the selected herbicides was provided by following both the variable fluorescence parameter $1-\mathrm{V}_{\mathrm{J}}$ and the oxygen evolution capacity, respectively, using a dual electrooptical transducer prototype (Biosensor srl, Via degli Olmetti, Rome, Italy). Algae were illuminated by a $350 \mu \mathrm{mol}$ photons $\mathrm{m}^{-2} \mathrm{~s}^{-1}$ light with repeated cycles of $30 \mathrm{~s}$ light excitation and $10 \mathrm{~min}$ dark. An applied potential of $-0.6 \mathrm{~V}$ was used with an acquirement interval of $0.5 \mathrm{~s}$. Herbicides were added into the electrochemical cell $\left(200 \mu \mathrm{L}\right.$ volume containing $50 \mathrm{mM}$ Tricine, $20 \mathrm{mM} \mathrm{CaCl}_{2}, 5 \mathrm{mM} \mathrm{MgCl}_{2}, 50 \mathrm{mM} \mathrm{NaCl}$, $70 \mathrm{mM}$ sucrose $\mathrm{pH}$ 7.2) in a concentration range from 1 to $100 \mu \mathrm{M}$ and the $1-\mathrm{V}_{\mathrm{J}}$ variations as well as the current signals due to oxygen reduction on the pCB-SPE working electrode were recorded in dependence to the target analyte concentrations.

\subsection{Biosensor prototypes}

The paper-based screen-printed electrode algae sensors were integrated into the dual electro-optical transduction prototype able of both optical and electrochemical analysis, projected and realised by the company Biosensor srl. The instrument is a portable prototype consisting of a module cell for the insertion of the paper-based screen-printed electrode hosting the biological material. The cell is equipped with a LED system (of $350 \mu \mathrm{mol}$ photons $\mathrm{m}^{-2} \mathrm{~s}^{-1}$ of red light at a $650 \mathrm{~nm}$ wavelength) which provide algae illumination and measure the fluorescence emission at $680 \mathrm{~nm}$ by a photodiode, automatically calculating the fluorescence parameters $\left(\mathrm{F}_{\mathrm{V}} / \mathrm{F}_{\mathrm{M}}\right.$ and $\left.1-\mathrm{V}_{\mathrm{J}}\right)$ according to the recorded Kautsky curves (Figure 1B). The red light covers a surface of $1 \mathrm{~cm}^{2}$, resulting in highly reproducible measurements averaged over 1000 points. The electrochemical set-up is constituted of a DC voltage supply, which provide a bias potential in the range of $\pm 0.800 \mathrm{~V}$ between the working and the reference electrodes, and an amperometer to detect the current intensity variation deriving from the algae oxygen evolution process (Figure 1C). The biological module, perfectly sealed, hosts the samples under test. Both static and dynamic operations are allowed thanks to an automatically controlled fluidic system equipped of inlet and outlet connections for the electrolytic/washing solution and sample flow. 


\section{Results And Discussion}

\subsection{A systematic characterisation of $C$. reinhardtii 28 strains}

With the aim to increase the selectivity of algae-based biosensors we propose a systematic study of a collection of 28 strains of the green alga $C$. reinhardtii to exploit as an array of biocomponent with different affinity towards diverse herbicide classes. The intention is to provide a multiplexing analysis of target analytes of agro-environmental interest by the evaluation of inhibition studies with solutions and mixtures of herbicides.

The choice of the bioreceptor during biosensor design is an essential phase, which deserves the right assessments in terms of sensitivity, repeatability, and stability among other analytical parameters. To meet these demands, many inspirations have been originated by docking and molecular genetics approaches, to obtain very sensitive and selective bioreceptors. In the last decades, more than 50 different $C$. reinhardtii algae strains have been collected in our laboratories and used for different purposes (e.g. nutraceutical, space research, and biosensing) (Giardi et al., 2013). This handbook on biosensor design started from the selection of 28 different strains of $C$. reinhardtii from this collection, obtained in previous studies by diverse techniques as cloning, mutagenesis, and biolistic transformation. Among them, $\mathrm{CC} 125$ is the wild type strain exploited as control (Elisabeth et al., 1987). This corresponds to the basic "137c" wild type (isolated in 1945 near Amherst MA, USA, by G.M. Smith) and is presumably equivalent to strain 11/32c (Culture Centre of Algae and Protozoa, location, country). CC125 is the background strain for many mutations, including CC503 cw92 mt+, which has been the source of DNA, used for genomic sequencing. $\mathrm{CC} 125$ has been kindly provided by the Chlamydomonas Collection, Duke University to UTEX in 1980 (UTEX 2244).

CW15 is a cell-wall mutant with a particular defect in cell wall production (Davies et al., 1971; Loppes et al., 1975).

The intron less (IL) strain has been produced from wild-type cells 11/32b using an efficient chloroplast transformation protocol. In particular, the highly conserved $p s b A$ gene has been manipulated, and a transformant with no introns in the $p s b A$ gene has been generated starting from wild-type cells $11 / 32 b$ (Sammlung von Algenkulturen, Grttingen, FRG). Starting from this strain, the deletion mutant FuD7 and the Del mutant have been obtained in previous studies as well as a collection of different mutants (Johanningmeier and Heiss, 1993). For this reason, IL is considered as a reference strain for the 25 D1 mutants selected for this protocol and reported in Table 1.

The selected 28 strains were physiologically characterised, by evaluating cell culture growth, pigment content, photosynthetic activity, oxygen evolution, and herbicide detection capability, with the aim to exploit them as bioreceptors for the realisation of a dual electro-optical transduction algal biosensor.

\subsubsection{Cell culture growth}


The growth of selected Chlamydomonas strains was characterized by measuring the optical density of the culture over a 165-hour period at a $750 \mathrm{~nm}$ wavelength. Figure 2 reports the time courses of all the 28strain culture growth, showing the difference among the grow rate of D1 mutants, the reference strain IL, the wild type control $\mathrm{CC} 125$, and the mutant $\mathrm{Cw} 15$. As shown, during the analysed period, absorbance values were found similar for most D1 mutants, and slightly higher for A153S, A250V, A251C, probably due to the particular amino acidic substitution, as well as for the wild type CC125 and cW15 mutant. Values are the average of 3 independent experiments $( \pm S E, n=3)$.

\subsubsection{Pigment content, Photosynthetic activity, and Oxygen evolution}

The pigment content of selected Chlamydomonas strains was analysed by following the chlorophyll a and $b$ accumulation of the cultures over a 165 -hour period under continuous light $\left(50 \mu \mathrm{mol}\right.$ photons $\mathrm{m}^{-2} \mathrm{~s}^{-}$ $\left.{ }^{1}\right)$, agitation ( $150 \mathrm{rpm}$ ) and $25^{\circ} \mathrm{C}$ temperature, obtained by $80 \%$ acetone extraction and spectrophotometrically measured as absorbance at a $652 \mathrm{~nm}$ wavelength. As depicted in Figure $3 \mathrm{~A}$, the chlorophyll content in the wild type CC125 was, in the majority of cases, more than three times as high as in most mutants, excluding IL and A250R. The photochemical efficiency of $C$. reinhardtii strains was evaluated by the fluorescence analysis of the chlorophyll a described by the OJIP or Kautsky profile $v s$ time, by which it is possible to calculate the characteristic photosynthetic parameters $F_{V} / F_{M}$ (maximum fluorescence yield of PSII) and 1- $\mathrm{V}_{\mathrm{J}}$ (relative variable fluorescence at $2 \mathrm{~ms}$ ). The values of these fluorescence parameters were reported in Figure 3B, calculated by each Kautsky curve and plotted as a function of time, to show the photosynthetic efficiency of the different strains in physiological conditions. These results evidence that some strains (e.g. CC125, IL, A250R, A250V, CW15, S264K) exhibit a higher photosynthetic activity in terms of maximum fluorescence yield in comparison with other strains (e.g. A153S, A250L, L159M, S212C among others) which show a reduction of this parameter. On the contrary, some strains, with a sufficient maximum fluorescence yield, show decreased values of the variable fluorescence parameter, as for example the strain S264K. In general, the variations of the photosynthetic parameters could be ascribed to a rearrangement of the photosynthetic apparatus due to the induced mutations in the $\mathrm{D} 1$ protein, as well as to a change in electron transfer rate along with the photosynthetic chain, in particular between the first electron acceptor $Q_{A}$ and the second one $Q_{B}$. As a result, the evident variation in shape of the OJIP curve of these mutants with respect to the control strain is directly attributable to the accumulation of reduced $Q_{A}$ and to the marked slowing of electron flow.

Oxygen evolution for the $28 \mathrm{C}$. reinhardtii strains was amperometrically measured on liquid cell cultures exploiting carbon black (CB) nanomodified screen-printed electrodes (SPEs) as a valid alternative to the conventional Clark electrode. CB nanoparticles, indeed, show their potential to sense oxygen reduction thanks to their ability to electrocatalyse the reduction of oxygen at lower potential than unmodified SPEs, with increase of sensitivity due to nanodimensions onion-like carbon structure, high number of defect sites and higher content in 0 atoms (Mazzaracchio et al., 2019; Arduini et al., 2010; Arduini et al., 2011; Arduini et al., 2020; Talarico et al., 2015). In this case, CB is able to measure oxygen produced within the photosynthetic process when algae are under illumination $\left(350 \mu \mathrm{mol}\right.$ photons $\left.\mathrm{m}^{-2} \mathrm{~s}^{-1}\right)$. The rate of oxygen 
evolution was measured for each strain at an applied potential of $-0.6 \mathrm{~V}$ after a period of $10 \mathrm{~min}$ of dark adaptation. As shown in Figure 3C, CC125, A250L and F255N strains exhibited the highest current signals up to $1.5 \mu \mathrm{A}$.

\subsubsection{Herbicide detection capability}

The response of the selected strains to triazine and urea type herbicides was studied by chlorophyll $a$ fluorescence induction curves (OJIP or Kautsky curve). The relative variable fluorescence at $2 \mathrm{~ms}$ at the characteristic point $J\left(V_{J}\right)$ gives a measure of the relative amount of the reduced $\mathrm{Q}_{A}$. Therefore, 1$V_{J}$ represents the fraction of oxidised $Q_{A}$ or the efficiency by which the electron is transferred from plastoquinone $Q_{A}$ to $Q_{B}$. In the presence of photosynthetic herbicides, the $Q_{B}$ binding site is permanently occupied by the inhibitor and electron transport does not extend beyond $Q_{A}$. The accumulation of reduced forms of $Q_{A}$ is proportional to the herbicide concentration and can be directly evaluated by the increase of the variable fluorescence level at point $J$, making the parameter $1-V_{J}$ one of the most sensitive for herbicide detection. Using this approach, we evaluate the sensitivity of the selected strains to atrazine, terbuthylazine, and diuron as case study herbicides. Figure $\mathbf{s} 1$ (Supplementary Materials) reports the fluorescence response of the 28 Chlamydomonas strains towards the 3 herbicides as Kautsky curves as well as calibration curves expressed as $1-V_{J} v s$ herbicide concentration. Moreover, with the aim to highlight the different sensitivity of all the strains, their response to a fixed herbicide concentration of 100 $\mathrm{nM}$ is reported in Figure 4, which underline how each strain demonstrates different inhibition of the photosynthetic activity in the presence of the herbicides.

Among other, L159V, L159M, L200I, I163N, I163S, I163T, P162S, S212C, S268C strains and the double mutant S209A/S212C showed the highest sensitivity to atrazine with a $50 \%$ of photosynthetic activity inhibition. While L159V presented the highest sensitivity to atrazine, CC125, IL, and S268C showed the highest sensitivity to terbuthylazine ( 50 \% inhibition). Whereas, S264K strain is resistant to triazine while very sensitive to urea herbicides. In addition, most strains are highly susceptible to diuron exposure, with an inhibition from 60 \% (e.g. for CC125, IL, A250L, A250R, and A251C) to 80 \% (for L159M, L200I, P162S, S268C). Notably, F255N strain showed high resistance to both herbicide classes.

The inhibition constant $\mathrm{IC}_{20}$ (herbicide concentration required for $20 \%$ inhibition of the parameter $1-\mathrm{V}_{\mathrm{J}}$ ) and detection limits were also calculated (Table 2 ) on the basis of $99 \%$ confidence interval, which, assuming the normal distribution of the data, corresponds to $2.6 \times$ standard error of the measurements $(\sigma)$, exploiting the modified relationship for the Langmuir absorption isotherm, $\mathrm{LOD}=2.6 \times \sigma \times \mathrm{IC}_{20} /(100-$

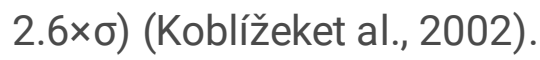

\subsection{C. reinhardtii immobilisation on paper-based SPEs}

Once assessed the physiological features of the selected strains, further experiments for the development of the dual electro-optical biosensor have been accomplished exploiting $C$. reinhardtii $\mathrm{CC} 125$ strain as a case study. 
A limiting step in the development of whole cell biosensors is the immobilization of the biomaterial in a matrix that prevents leaching, without reducing the stability and activity of the cells. Several methods are currently available for cell immobilisation, with entrapment as the most frequently used. With the scope to enhance the yield in the production of working algae-sensors as well as to achieve a higher repeatability in algae-sensor preparation, algal whole cells were immobilised on paper-based screenprinted electrodes modified with carbon black nanomaterials (paper-SPEs). The rationale behind the choice of using electrodes printed on paper consists of capturing algal whole cells into a 3D matrix composed of a natural polymer, thus providing a comfortable environmental for cells accommodation guaranteeing a better algae survival as well as an effective diffusion across the matrix of the target analyte.

To this aim, whole cells of $C$. reinhardtii CC125 were immobilised on the working electrode surface of paper-based screen-printed electrodes nanomodified with carbon black (paper-SPEs). To preserve the algae photosynthetic functionality, cells were entrapped in a calcium/alginate matrix. Thus, $1.2 \times 10^{7}$ cells of CC125 are suspended in $50 \mathrm{~mL}$ of $1 \%$ sodium alginate and $100 \mathrm{~mL}$ of $50 \mathrm{mM}$ Tricine, $20 \mathrm{mM}$ $\mathrm{CaCl}_{2}, 5 \mathrm{mM} \mathrm{MgCl}_{2}, 70 \mathrm{mM}$ sucrose $\mathrm{pH}$ 7.2. Then, $5 \mathrm{~mL}$ of this suspension were drop cast on the working electrode of the SPE and then cross-linked using $5 \mathrm{~mL}$ of $200 \mathrm{mM} \mathrm{CaCl}_{2}$ in the same buffer, obtaining a final number of cells of $4 \times 10^{5}$. This calcium alginate matrix can provide a biocompatible environment for algae entrapment, without collateral effect on their metabolism; at the same time, its porous network guarantees a good diffusion of the target analyte. The algae/pCB-SPEs were thus stored in $200 \mathrm{mM}$ $\mathrm{CaCl}_{2}$ in $50 \mathrm{mM}$ Tricine, $20 \mathrm{mM} \mathrm{CaCl}_{2}, 5 \mathrm{mM} \mathrm{MgCl}_{2}, 70 \mathrm{mM}$ sucrose $\mathrm{pH} 7.2$ under continuous light at 50

$\mu \mathrm{mol}$ photons $\mathrm{m}^{-2} \mathrm{~s}^{-1}$ for successive measurements. Each algae/paper-SPE was then accommodated into the measurement cells of the electro-optical transducer for the electrochemical analysis. SEM analysis and storage stability were performed to characterise the implemented algae-SPE sensors in depth (Figure $5 A$ and $5 B$, respectively).

\subsection{Study on different (nano)modified SPEs and working stability}

Different screen-printed electrodes modified with diverse (nano)materials were exploited to evaluate the best material for the analysis of the current signals coming from the algae oxygen evolution, including carbon black, carbon nanotubes, gold, gold nanoparticles, reduced graphene oxide, and poly (3,4ethylenedioxythiophene) (PEDOT). Results reported in Figure 6A highlight how carbon black represents the best choice, as this nanomaterial is able to enhance the electron transfer between algae evolved oxygen and the working electrodes, thus amplifying the current signals, especially in comparison with other (nano)materials.

Once selected the best nanomodified SPE, working stability of CC125 C. reinhardtii in solution and immobilised on paper-based SPEs modified with carbon black (pCB-SPEs) was evaluated by both amperometric and fluorescence analysis, run for many hours at room temperature, under repeated cycles of 10 min dark and $30 \mathrm{~s}$ light $\left(350 \mu \mathrm{mol}\right.$ photons $\left.\mathrm{m}^{-2} \mathrm{~s}^{-1}\right)$ in a measurement volume of $200 \mathrm{~mL}$ of $50 \mathrm{mM}$ Tricine, $20 \mathrm{mM} \mathrm{CaCl}_{2}, 5 \mathrm{mM} \mathrm{MgCl}_{2}, 50 \mathrm{mM} \mathrm{NaCl}, 70 \mathrm{mM}$ sucrose $\mathrm{pH}$ 7.2. Figure $6 \mathrm{~B}$ shows $100 \%$ of light- 
induced oxygen evolution activity up to ca. 8-10 hours, with a progressive decrease of signal later on. This indicates not only a very good operational stability but also a high intra-electrode repeatability with RSD of $1.1 \%(n=12)$. However, there is a clear difference between the signal stability of algae in solution and immobilised, evidencing that the immobilisation confers a higher robustness of the sensor. Figure $\mathbf{6 C}$ reports the Kautsky profiles of algae in solution as well as immobilised, underlining that the algae photosynthetic activity slightly suffers from the immobilisation while remaining constant during the 8-10 hours of the stability test.

\subsection{Reversibility, matrix effect, and interferents}

To gain further insights on the evaluation of the diverse analytical parameters, tests were performed to evaluate the nature of herbicide inhibition by both amperometric (Figure 7A) and fluorescence analysis (Figure 7D), exploiting atrazine as case study. These tests consist in washing the algae/pCB-SPE with 50 $\mathrm{mM}$ Tricine, $20 \mathrm{mM} \mathrm{CaCl}_{2}, 5 \mathrm{mM} \mathrm{MgCl}_{2}, 50 \mathrm{mM} \mathrm{NaCl}, 70 \mathrm{mM}$ sucrose $\mathrm{pH} 7.2$ after the measurement of the inhibition at an atrazine concentration of $6.6 \mathrm{mM}$, for the electrochemical analysis, and $100 \mathrm{nM}$, for the optical one, to record both the recovered current and fluorescence signals. As reported in Figure 7AVD, a complete recovery of both algae oxygen evolution and photosynthetic activity occurred.

To investigate the suitability of the proposed biosensor in real samples, matrix effect and recovery studies were also provided. To estimate matrix effect by the electrochemical point of view, algae/pCBSPEs were incubated in $200 \mathrm{~mL}$ of $2 \times$ buffer $\left(100 \mathrm{mM}\right.$ Tricine, $20 \mathrm{mM} \mathrm{CaCl}_{2}, 5 \mathrm{mM} \mathrm{MgCl}, 50 \mathrm{mM} \mathrm{NaCl}$, $70 \mathrm{mM}$ sucrose pH 7.2) diluted 1:2 (v:v) in surface water (Sebou River, Morocco) and fortified with atrazine in a concentration range from 0.1 to $41.6 \mu \mathrm{M}$. Calibration curves were obtained for both standard solutions and real samples, described by the equations $y=0.98( \pm 0.01)-0.06( \pm 0.003) \times\left(R^{2}=0.9952\right)$ and $y=0.98( \pm 0.01)-0.09( \pm 0.005) \times\left(R^{2}=0.9945\right)$, respectively (Figure 7B). The biosensor response was in the linear range from 0.1 to $6.6 \mu \mathrm{M}$ atrazine and showed a detection limit of $2 \mathrm{nM}$. The ratio between slopes of the calibration curves obtained in standard solutions and real samples was equal to 0.72 , indicating a moderate dependence from surface water matrix (28 \%). The calibration curve obtained for the electrochemical algal biosensor challenged in real samples was further used to calculate the recovery values of the surface water samples. Recovery values of $106.6 \pm 10 \%$ and $96 \pm 8 \%$ were obtained for 3 and $5 \mathrm{mM}$ of atrazine, respectively, highlighting a satisfactory capability to detect atrazine also in surface water.

Regarding the fluorescence analysis, tap water was exploited as real environmental matrix fortified with atrazine in a nanomolar concentration range. Calibration curves were obtained for both standard solutions and real samples, described by the equations $y=0.516( \pm 0.005)-0.0012( \pm 0.00006) \times\left(R^{2}=\right.$ $0.9854)$ and $y=0.518( \pm 0.003)-0.0013( \pm 0.00003) \times\left(R^{2}=0.9963\right)$, respectively (Figure 7E). The biosensor response was in the linear range from 10 to $200 \mathrm{nM}$ atrazine and showed a detection limit of 5 $\mathrm{pM}$. The slopes of the calibration curves obtained in standard solutions and real samples were very similar with a ratio of 0.92 , indicating a slight dependence from the tap water matrix. The calibration curve obtained for the optical transduction challenged in real samples was further used to calculate the 
recovery values of the tap water samples. A recovery value of $96 \pm 5 \%$ was obtained for $75 \mathrm{nM}$ of atrazine, highlighting a satisfactory capability to detect atrazine also in tap water.

It is crucial to point out the observation of the different detection limits obtained for the two detection methods exploited, highlighting that the optical transduction provides atrazine analysis in the nanomolar range while the electrochemical one in the micromolar range.

With the aim to challenge the capability of the proposed algal biosensor in real environmental water samples, some chemicals including metals, pesticides, and phenolic compounds were tested as interferences at legal limits established by the EU Directive 2013/39/EU for surface water (where present). In detail, algae/pCB-SPEs were incubated in $200 \mathrm{~mL}$ of $50 \mathrm{mM}$ Tricine, $20 \mathrm{mM} \mathrm{CaCl}, 5 \mathrm{mM} \mathrm{MgCl}_{2}, 50$ $\mathrm{mM} \mathrm{NaCl}, 70 \mathrm{mM}$ sucrose $\mathrm{pH} 7.2$ fortified with standard solutions of $100 \mathrm{ppb}$ arsenic, $20 \mathrm{ppb}$ copper, 5 ppb cadmium, $10 \mathrm{ppb}$ lead, $10 \mathrm{ppb}$ bisphenol A, $1 \mathrm{ppb}$ paraoxon, and $6.6 \mathrm{mM}$ atrazine, terbuthylazine, and diuron, as well as with a solution spiked with all the above listed compounds, to evaluate the synergistic effect of different chemicals in a mixture. Results reported in Figure 7C and 7F highlight that the interfering species did not affect the analysis of atrazine at the exploited concentrations in both electrochemical and fluorescence analysis.

\section{Conclusions}

Main issues related to the development of algal-based biosensors were addressed and mitigated in this study. In particular, the exploitation of a multi-array platform boosted to increase the selectivity, up to now referred to as a main concern (Husu et al., 2013). First attempts have already been made in previous works, in which the multi-selectivity of the platform was due to the presence of biorecognition elements from different sources (both enzymes and algae cells) towards diverse targets (Scognamiglio et al., 2013). For the first time, here we focus on the exclusive use of algae whole cells, proposing the design of an array platform of bioreceptors for the simultaneous detection of different classes of herbicides by a systematic study of a $C$. reinhardtii algae collection. The concept of using the array of algae strains relies on the difference in the response behaviour of the individual bioreceptor towards diverse herbicide classes; therefore, it was interesting to compare the inhibition results of all the 28 strains to get differentiated information about the presence of pollutants or groups of them.

Another important drawback hindering the success of algae-based biosensors is represented by the low repeatability of the algae-sensor fabrication, strictly related to cells preparation and immobilization on the selected surface, e.g. filter paper and screen-printed electrodes. For this reason, many amendments on protocols, already reported in the literature on this topic, are made, and positive feedbacks obtained as shown by the experimental data above reported. The first delicate step is the harvesting of $C$. reinhardtii cells. In the present study, the conditions of algae centrifugation were modified by lowering speed from 5000 to $2000 \mathrm{~g}$ as well as reducing centrifugation time from 10 to $5 \mathrm{~min}$, making this preparation step much softer and less destructive for the cells. In addition, number of cells (from $10^{6}$ to $10^{7} \mathrm{cells} / \mathrm{ml}$ ), and 
content of chlorophylls (from $8 \mu \mathrm{g} / \mathrm{ml}$ to $10 \mu \mathrm{g} / \mathrm{ml}$ ) were increased to enrich the biological material to be immobilised.

Furthermore, the addition of alginate and calcium chloride represents another important critical aspect, and reducing the concentration of alginate from 2 to $1 \%(\mathrm{w} / \mathrm{v})$ allows to improve algae performance and thus to increase the repeatability of sensor preparation. Indeed, these new favourable conditions furnished a suitable behaviour and thus a better vitality of the cells, and, at the same time, a less dense porous network guaranteed a good diffusion of the target analytes. This led to a higher repeatability in algae-sensor preparation with RSD of $5 \%(n=100)$ in comparison with previous results.

In this overall scenario, the proposed biosensor shows many advantages in comparison with most photosynthetic biosensing systems available in literature, in terms of sensitivity, repeatability, working and storage stability, and capability to operate in real water matrices.

On the other hand, a main challenge emerged from this immobilisation protocol, that is cell leaching from the supports, especially in the case of filter paper. Indeed, despite significant advantages of sustainability, affordability and effectiveness of paper-based algae sensors, they can actually be exploited only for static measurements. In fact, leaching phenomenon occurs in dynamic analysis, probably due to a weak cells adhesion on the support. This will commit our group to carry out new trials, aimed at developing a new immobilisation protocol devoted to measures in fluidics. In this context, further perspectives can be addressed towards the development of sandwich-type polymeric films for a stronger embedding of algae cells into the support, eventually also constituted of nanomaterials (i.e. graphene) for the improvement of both cell adhesion and photosynthetic/analytical performances.

\section{Declarations}

Ethics approval and consent to participate: Not applicable

Consent for publication: Not applicable

Availability of data and materials: All data generated or analysed during this study are included in this published article within each editable graph.

\section{Competing interests}

The authors declare that they have no known competing financial interests or personal relationships that could have appeared to influence the work reported in this paper.

\section{Authors' contributions}

V. Scognamiglio, F. Arduini, A. Amine and M.T. Giardi: conceived, designed and refined the methods. A. Antonacci and R. Attaallah: performed the experimental section. V. Scognamiglio: wrote this manuscript. 
This work is supported by ALGAE-CB Bilateral Project Italy-Morocco 2018/2019 within the Joint Research Projects Programme of the Italian National Research Council. This work is also supported by NanoSWS project EraNetMed-RQ3-2016 and AdSWiM Interreg Project Italy-Croatia 2019/2020. Authors express gratitude to Ing. Francesco Gallucci (CRA-ING, CREA, Consiglio Ricerca Agricoltura e Analisi Economia Agraria) for his precious support in SEM analysis. The authors thanks Prof. Udo Johanningmeier, from Martin-Luther-Universität Halle-Wittenberg, Institut für Pflanzenphysiologie, Weinbergweg, Germany for the design/production and the kind supply of $C$. reinhardtii mutants.

\section{References}

Agenda Item 19 A/RES/74/4 (2019). Political Declaration of the High-Level Political Forum on Sustainable Development Convened under the Auspices of the General Assembly, Seventy-Fourth Sess. pp. 1-6, 10.1017/S002081830002561.

Antonacci, A. \& Scognamiglio, V. Biotechnological Advances in the Design of Algae-Based Biosensors. Trends Biotechnol. 38, 1-14 (2019).

Arduini, F., Amine, A., Majorani, C., Di Giorgio, F., De Felicis, D., Cataldo, F., Palleschi, G. (2010). High performance electrochemical sensor based on modified screen-printed electrodes with cost-effective dispersion of nanostructured carbon black. Electrochemistry Communications, 12(3), 346-350.

Arduini, F., Majorani, C., Amine, A., Moscone, D. Palleschi, G. Hg ${ }^{2+}$ detection by measuring thiol groups with a highly sensitive screen-printed electrode modified with a nanostructured carbon black film. Electrochim. Acta 56, 4209-4215 (2011).

Arduini, F., Micheli, L., Scognamiglio, V., Mazzaracchio, V. \& Moscone, D. Sustainable materials for the design of forefront printed (bio)sensors applied in agrifood sector. TrAC Trends Anal. Chem. (2020).

Arduini, F., Cinti, S., Mazzaracchio, V., Scognamiglio, V., Amine, A., Moscone, D. (2020). Carbon black as an outstanding and affordable nanomaterial for electrochemical (bio) sensor design. Biosensors and Bioelectronics, 156, 112033.

Attaallah, R., Antonacci, A., Mazzaracchio, V., Moscone, D., Palleschi, G., Arduini, F., Scognamiglio, V. (2020). Carbon black nanoparticles to sense algae oxygen evolution for herbicides detection: Atrazine as a case study. Biosensors and Bioelectronics, 112203.

Bartolucci, C., Antonacci, A., Arduini, F., Moscone, D., Fraceto, L., Campos, E., Santander, J. M. P. (2020). Green nanomaterials fostering agrifood sustainability. TrAC Trends in Analytical Chemistry, 125, 115840.

Cooper, Geoffrey M., R. E. H. The Cell: A Molecular Approach. Medicinska naklada (2004).

Davies, D. R. \& Plaskitt, A. Genetical and structural analyses of cell-wall formation in Chlamydomonas reinhardi. Genet. Res. 17, 33-43 (1971). 
Elisabeth, P., Silvia, H., Johanningmeier, U., Achim, T. Site-Specific Mutagenesis of the D1 Subunit of Photosystem II in Wild-Type Chlamydomonas. Biosystems 262, 10678-10683 (1987).

Eurostat report 2020: Agri-environmental indicator - consumption of pesticides. https://ec.europa.eu/eurostat/statistics-explained/index.php/Agri-environmental_indicator__consumption_of_pesticides.

Giardi, M. T., Rea, G., Lambreva, M. D., Antonacci, A., Pastorelli, S., Bertalan, I., Mattoo, A. K. (2013). Mutations of photosystem II D1 protein that empower efficient phenotypes of Chlamydomonas reinhardtii under extreme environment in space. Plos one, 8(5), e64352.

Giardi, M. T., Scognamiglio, V., Rea, G., Rodio, G., Antonacci, A., Lambreva, M., ... \& Johanningmeier, U. (2009). Optical biosensors for environmental monitoring based on computational and biotechnological tools for engineering the photosynthetic D1 protein of Chlamydomonas reinhardtii. Biosensors and Bioelectronics, 25(2), 294-300.

Husu, I., Rodio, G., Touloupakis, E., Lambreva, M. D., Buonasera, K., Litescu, S. C., Rea, G. (2013). Insights into photo-electrochemical sensing of herbicides driven by Chlamydomonas reinhardtii cells. Sensors and Actuators B: Chemical, 185, 321-330.

Johanningmeier, U. \& Heiss, S. Construction of a Chlamydomonas reinhardtii mutant with an intronless psbA gene. Plant Mol. Biol. 22, 91-99 (1993).

Koblížek, M., Malý, J., Masojídek, J., Komenda, J., Kučera, T., Giardi, M. T., Pilloton, R. (2002). A biosensor for the detection of triazine and phenylurea herbicides designed using Photosystem II coupled to a screen-printed electrode. Biotechnology and bioengineering, 78(1), 110-116.

Kyte, J. \& Doolittle, R. F. A simple method for displaying the hydropathic character of a protein. J. Mol. Biol. 157, 105-132 (1982).

Loppes, R. \& R.D. Changes in Phosphatase Activity Associated with Cell Wall Defects in Chlamydomonas reinhard. Arch. Microbiol. 103, 417-426 (1975).

Mazzaracchio, V., Tomei, M. R., Cacciotti, I., Chiodoni, A., Novara, C., Castellino, M., Arduini, F. (2019). Inside the different types of carbon black as nanomodifiers for screen-printed electrodes. Electrochimica Acta, 317, 673-683.

Rea, G., Lambreva, M., Polticelli, F., Bertalan, I., Antonacci, A., Pastorelli, S., Giardi, M. T. (2011). Directed evolution and in silico analysis of reaction centre proteins reveal molecular signatures of photosynthesis adaptation to radiation pressure. PloS one, 6(1), e16216.

Scognamiglio, V., Pezzotti, I., Pezzotti, G., Cano, J., Manfredonia, I., Buonasera, K., Giardi, M. T. (2013). A new embedded biosensor platform based on micro-electrodes array (MEA) technology. Sensors and Actuators B: Chemical, 176, 275-283. 
Scognamiglio, V., Antonacci, A., Arduini, F., Moscone, D., Campos, E. V., Fraceto, L. F., Palleschi, G. (2019). An eco-designed paper-based algal biosensor for nanoformulated herbicide optical detection. Journal of hazardous materials, 373, 483-492.

Sections 201/409 of Federal Food, Drug, and Cosmetic Act, (2018) https://www.fda.gov/Food/IngredientsPackagingLabeling/GRAS/.

Talarico, D., Arduini, F., Constantino, A., Del Carlo, M., Compagnone, D., Moscone, D., Palleschi, G. (2015). Carbon black as successful screen-printed electrode modifier for phenolic compound detection. Electrochemistry Communications, 60, 78-82.

\section{Tables}

Table 1. List of the D1 site directed mutants selected for the systematic characterisation of potential biorecognition element. The amino acidic substitution and properties are indicated, as well as mutation position respect the D1 protein structure. The hydropathic index is cited as in Kite et al. 1982; the amino acid classification in reactivity classes is according to the increase reactivity towards reactive oxygen species, and is done according to Cooper et al. 2004, the side chain polarity is presented according to Rea et al. 2011. 


\begin{tabular}{|c|c|c|c|c|c|c|c|}
\hline \multirow{3}{*}{$\begin{array}{l}\text { ite directed } \\
\text { Mutants } \\
\text { A153S }\end{array}$} & \multirow{3}{*}{$\begin{array}{c}\text { WT } \\
\text { alanine }\end{array}$} & \multirow{3}{*}{$\begin{array}{r}\text { Mutant } \\
\text { serine }\end{array}$} & \multicolumn{4}{|c|}{$\begin{array}{l}\text { Hydropathic index/reactivity class/side } \\
\text { chain polarity }\end{array}$} & \multirow{3}{*}{$\begin{array}{l}\text { Localization of the mutation in } \\
\text { the protein D1 } \\
\text { in the helix III of D1 }\end{array}$} \\
\hline & & & \multicolumn{2}{|c|}{ WT } & \multicolumn{2}{|c|}{ Mutant } & \\
\hline & & & 1.8 (II) & nonpolar & $\begin{array}{c}-0.8 \\
(0)\end{array}$ & polar & \\
\hline A250L & alanine & leucine & 1.8 (II) & nonpolar & $\begin{array}{l}3.8 \\
(\mathrm{IV})\end{array}$ & nonpolar & in the stroma loop II \\
\hline A250R & alanine & arginine & 1.8 (II) & nonpolar & $\begin{array}{l}-4.5 \\
(0)\end{array}$ & polar & in the stroma loop II \\
\hline A250V & alanine & valine & 1.8 (II) & nonpolar & $\begin{array}{l}4.2 \\
\text { (III) }\end{array}$ & nonpolar & in the stroma loop II \\
\hline A251C & alanine & cysteine & 1.8 (II) & nonpolar & $\begin{array}{l}2.5 \\
(\mathrm{~V})\end{array}$ & polar & in the stroma loop II \\
\hline $82 \mathrm{M} / \mathrm{I} 184 \mathrm{M}$ & $\begin{array}{l}\text { phenylalanine } \\
\text { isoleucine }\end{array}$ & $\begin{array}{l}\text { methionine } \\
\text { methionine }\end{array}$ & $\begin{array}{l}2.8 \\
(\mathrm{VI}) \\
4.5 \\
(\mathrm{IV})\end{array}$ & $\begin{array}{l}\text { nonpolar } \\
\text { nonpolar }\end{array}$ & $\begin{array}{l}1.9 \\
(\mathrm{~V}) \\
1.9 \\
(\mathrm{~V})\end{array}$ & $\begin{array}{l}\text { nonpolar } \\
\text { nonpolar }\end{array}$ & in the helix $\mathrm{V}$ of $\mathrm{D} 1$ \\
\hline F255N & phenylalanine & asparagine & $\begin{array}{l}2.8 \\
(\mathrm{VI})\end{array}$ & nonpolar & $\begin{array}{c}-3.5 \\
(0)\end{array}$ & polar & in the stroma loop II \\
\hline F265S & phenylalanine & serine & $\begin{array}{l}2.8 \\
(\mathrm{VI})\end{array}$ & nonpolar & $\begin{array}{c}-0.8 \\
(0)\end{array}$ & polar & in the II stroma loop \\
\hline F265T & phenylalanine & threonine & $\begin{array}{l}2.8 \\
(\mathrm{VI})\end{array}$ & nonpolar & $\begin{array}{l}-0.7 \\
(0)\end{array}$ & polar & in the II stroma loop \\
\hline G207S & glycine & serine & $-0.4(\mathrm{I})$ & nonpolar & $\begin{array}{c}-0.8 \\
(0)\end{array}$ & polar & in the helix IV of D1 \\
\hline L159I & leucine & isoleucine & $\begin{array}{l}3.8 \\
(\mathrm{IV})\end{array}$ & nonpolar & $\begin{array}{l}4.5 \\
(\mathrm{IV})\end{array}$ & nonpolar & near to Tyr 161 \\
\hline L159V & leucine & valine & $\begin{array}{l}3.8 \\
\text { (IV) }\end{array}$ & nonpolar & $\begin{array}{c}4.2 \\
\text { (III) }\end{array}$ & nonpolar & near to Tyr 161 \\
\hline L159M & leucine & methionine & $\begin{array}{l}3.8 \\
\text { (IV) }\end{array}$ & nonpolar & $\begin{array}{l}1.9 \\
(\mathrm{~V})\end{array}$ & nonpolar & near to Tyr 161 \\
\hline L200I & leucine & isoleucine & $\begin{array}{l}3.8 \\
\text { (IV) }\end{array}$ & nonpolar & $\begin{array}{l}4.5 \\
\text { (IV) }\end{array}$ & nonpolar & in the helix IV of D1 \\
\hline I163F & isoleucine & phenylalanine & $\begin{array}{l}4.5 \\
\text { (IV) }\end{array}$ & nonpolar & $\begin{array}{l}2.8 \\
(\mathrm{VI})\end{array}$ & nonpolar & near to Tyr 161 \\
\hline $\mathrm{I} 163 \mathrm{~N}$ & isoleucine & asparagine & $\begin{array}{l}4.5 \\
\text { (IV) }\end{array}$ & nonpolar & $\begin{array}{c}-3.5 \\
(0)\end{array}$ & polar & near to Tyr 161 \\
\hline I163S & isoleucine & serine & $\begin{array}{l}4.5 \\
\text { (IV) }\end{array}$ & nonpolar & $\begin{array}{c}-0.8 \\
(0)\end{array}$ & polar & near to Tyr 161 \\
\hline $\mathrm{I} 163 \mathrm{~T}$ & isoleucine & threonine & $\begin{array}{l}4.5 \\
\text { (IV) }\end{array}$ & nonpolar & $\begin{array}{c}-0.7 \\
(0)\end{array}$ & polar & near to Tyr 161 \\
\hline $\mathrm{I} 281 \mathrm{~T}$ & isoleucine & threonine & $\begin{array}{l}4.5 \\
\text { (IV) }\end{array}$ & nonpolar & $\begin{array}{c}-0.7 \\
(0)\end{array}$ & polar & in the helix V of D1 \\
\hline M172L & methionine & leucine & $1.9(\mathrm{~V})$ & nonpolar & $\begin{array}{l}3.8 \\
\text { (IV) }\end{array}$ & nonpolar & near to OEC \\
\hline P162S & proline & serine & $\begin{array}{l}-1.6 \\
\text { (III) }\end{array}$ & nonpolar & $\begin{array}{c}-0.8 \\
(0)\end{array}$ & polar & near to Tyr 161 \\
\hline $\mathrm{S} 212 \mathrm{C}$ & serine & cysteine & $-0.8(0)$ & polar & $\begin{array}{l}2.5 \\
(\mathrm{~V})\end{array}$ & polar & in the helix IV of D1 \\
\hline S264K & serine & lysine & $-0.8(0)$ & polar & $\begin{array}{c}-3.9 \\
(0)\end{array}$ & polar & in the stroma loop II \\
\hline S268C & serine & cysteine & $-0.8(0)$ & polar & $\begin{array}{l}2.5 \\
(\mathrm{~V})\end{array}$ & polar & in the stroma loop II \\
\hline
\end{tabular}




\begin{tabular}{|c|c|c|c|c|c|c|c|}
\hline :09A/S212C & $\begin{array}{l}\text { serine } \\
\text { serine }\end{array}$ & $\begin{array}{l}\text { alanine } \\
\text { cysteine }\end{array}$ & $\begin{array}{l}-0.8(0) \\
-0.8(0)\end{array}$ & $\begin{array}{l}\text { polar } \\
\text { polar }\end{array}$ & $\begin{array}{l}1.8 \\
\text { (II) } \\
2.5 \\
\text { (V) }\end{array}$ & $\begin{array}{c}\text { nonpolar } \\
\text { polar }\end{array}$ & in the helix IV of D1 \\
\hline
\end{tabular}

Table 2. Limits of detection of $C$. reinhardtii selected strains to three different photosynthetic herbicides.

\begin{tabular}{|c|c|c|c|}
\hline & Atrazine & Terbuthylazine & Diuron \\
\hline & $L O D p M$ & $L O D p M$ & $L O D p M$ \\
\hline CC125 & 33 & 32 & 32 \\
\hline IL & 32 & 29 & 23 \\
\hline A153S & 46 & 23 & 35 \\
\hline A250L & 45 & 15 & 28 \\
\hline A250R & 23 & 26 & 26 \\
\hline A250V & $\boldsymbol{R}$ & 27 & 40 \\
\hline A251C & 60 & 41 & 31 \\
\hline CW15 & 47 & 33 & 47 \\
\hline F182M/I184M & $\boldsymbol{R}$ & $\boldsymbol{R}$ & 27 \\
\hline F255N & $R$ & 84 & 14 \\
\hline F265S & 41 & 86 & 17 \\
\hline F265T & $R$ & 46 & 14 \\
\hline G207S & 79 & 79 & 21 \\
\hline L159I & 16 & 26 & 21 \\
\hline L159V & 15 & 20 & 13 \\
\hline L159M & 33 & 73 & 18 \\
\hline L200I & 21 & 14 & 13 \\
\hline I163F & $\boldsymbol{R}$ & 26 & 29 \\
\hline I163N & 17 & 17 & 14 \\
\hline I163S & 21 & 27 & 15 \\
\hline I163T & 14 & 26 & 27 \\
\hline $\mathrm{I} 281 \mathrm{~T}$ & 25 & 25 & 14 \\
\hline M172L & 31 & 25 & 23 \\
\hline P162S & 15 & 14 & 13 \\
\hline $\mathrm{S} 212 \mathrm{C}$ & 32 & 26 & 15 \\
\hline S264K & $\boldsymbol{R}$ & 14 & 18 \\
\hline S268C & 47 & 26 & 14 \\
\hline S209A/S212C & 29 & 45 & 25 \\
\hline
\end{tabular}

Legend: $R$ resistant

Figures 
$\mathbf{A}$

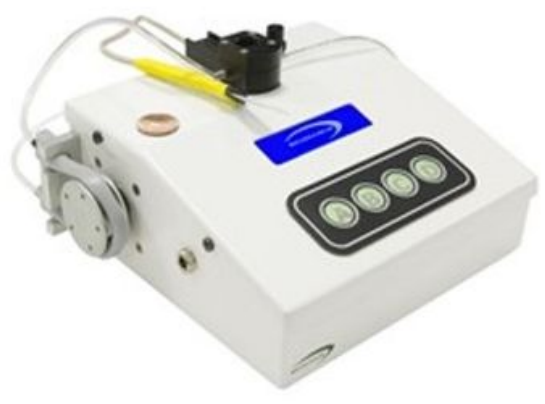

B

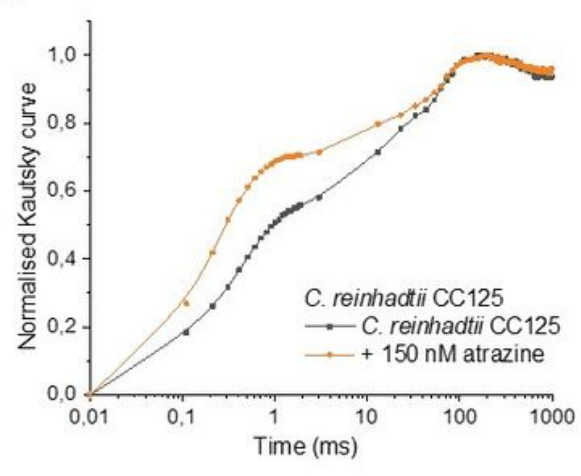

C

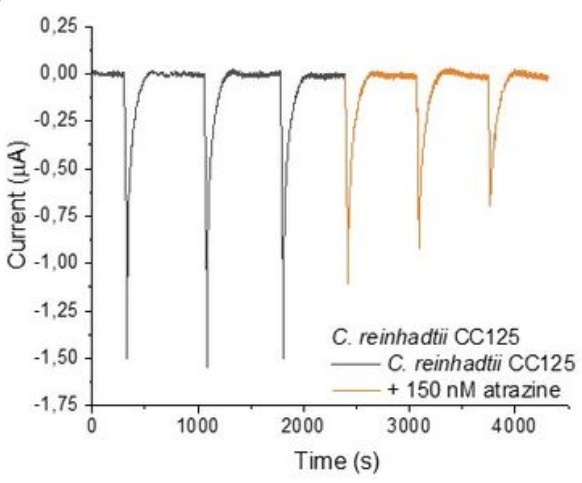

Figure 1

Dual electro-optical transducer prototype (A) for the measurement of the chlorophyll a fluorescence (B) and for the measurement of the current signals of algae under light illumination (C).

a

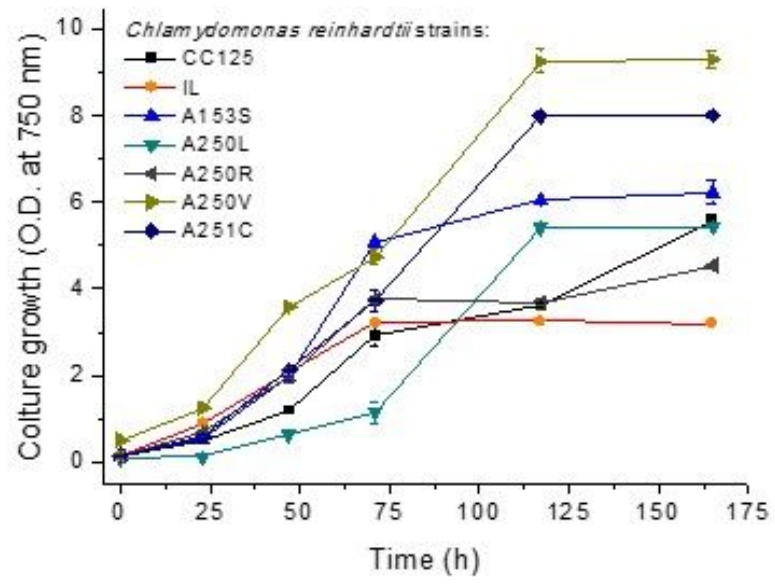

c

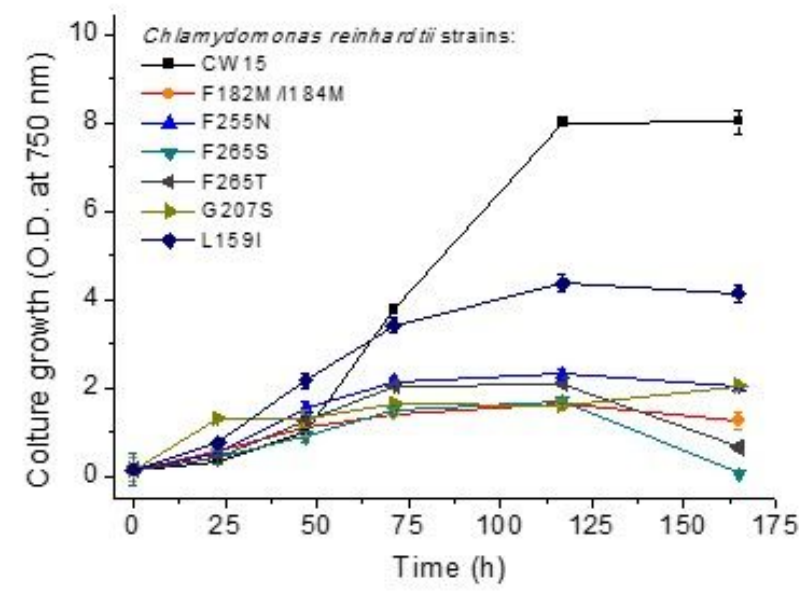

b

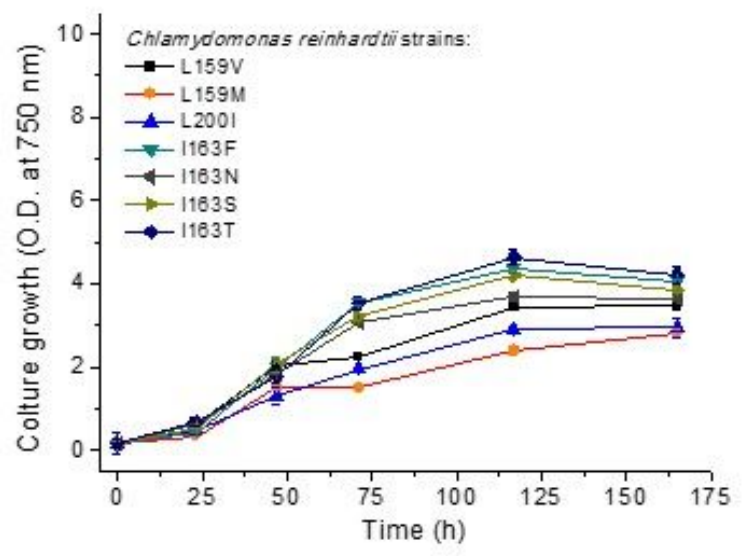

d

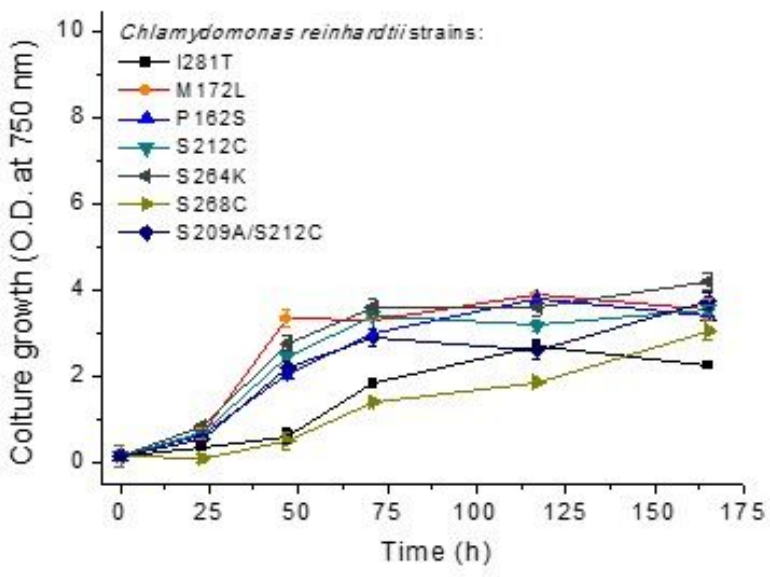

Figure 2 
Growth curve of C. reinhardtii 28 strains reported in Table 1, measuring the optical density (O.D.) of the cell suspension at $750 \mathrm{~nm}$ wavelength. Cells are growth in TAP at $25^{\circ} \mathrm{C}$ under continuous light $50 \mu \mathrm{mol}$ photons m-2 s-1 and continuous stirring at $150 \mathrm{rpm}(\mathrm{n}=3)$.
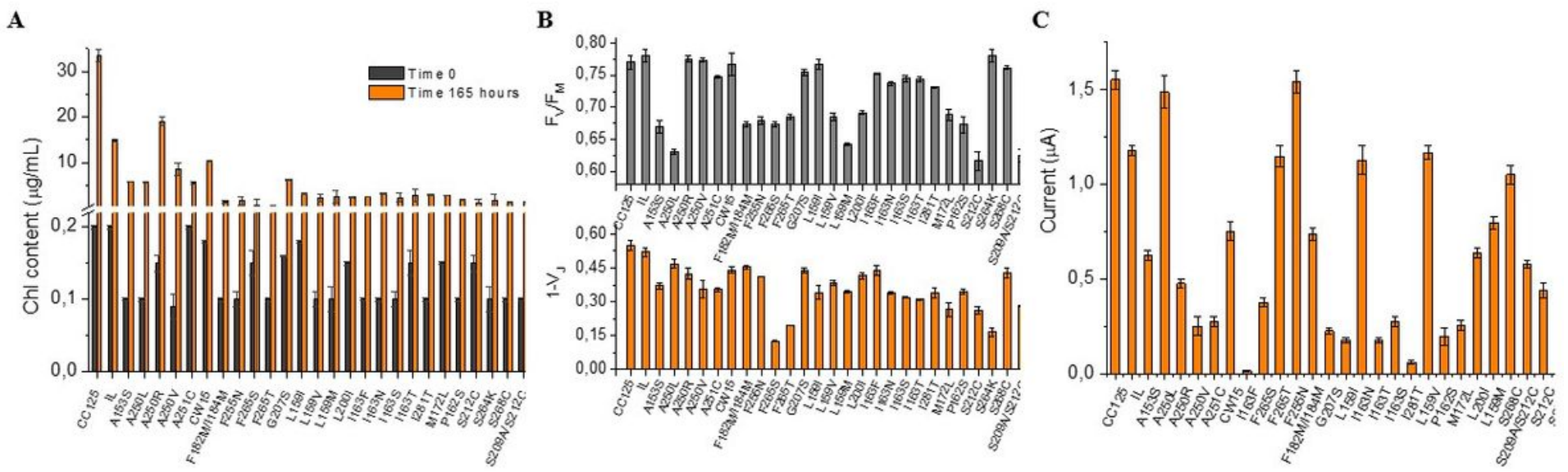

\section{Figure 3}

A) C. reinhardtii 28 strains pigment content calculated on the basis of the chlorophyll extract optical density (O.D.) at $652 \mathrm{~nm}$ wavelength. B) FV/FM and 1-VJ values. C) Oxygen evolution measured by CBSPEs. Cell cultures at early mid-exponential phase (Abs750=0.5 O.D., 106 cells $/ \mathrm{mL}$, and $5 \mu \mathrm{g} / \mathrm{mL}$ chlorophyll content) grown under $50 \mu \mathrm{mol} \mathrm{m}-2 \mathrm{~s}-1$ continuous light at $25^{\circ} \mathrm{C}$ and continuous stirring at 150 rpm (n=3).
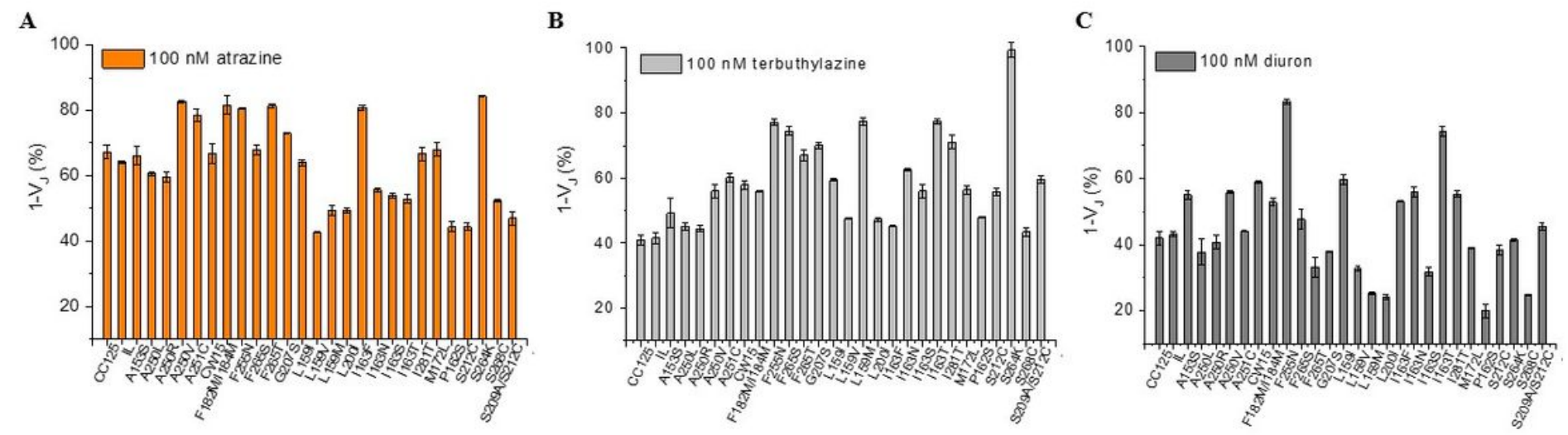

\section{Figure 4}

Response of the $28 \mathrm{C}$. reinhardtii strains reported in Table 1 to a $100 \mathrm{nM}$ concentration of atrazine (A), terbuthylazine (B), and diuron (C) $(n=3)$. Cell cultures at early mid-exponential phase (Abs $750=0.5$ O.D., 106 cells $/ \mathrm{mL}$, and $5 \mu \mathrm{g} / \mathrm{mL}$ chlorophyll content) grown under $50 \mu \mathrm{mol} \mathrm{m}-2 \mathrm{~s}-1$ continuous light at $25^{\circ} \mathrm{C}$ and continuous stirring at $150 \mathrm{rpm}(\mathrm{n}=3)$. 
$\mathbf{A}$

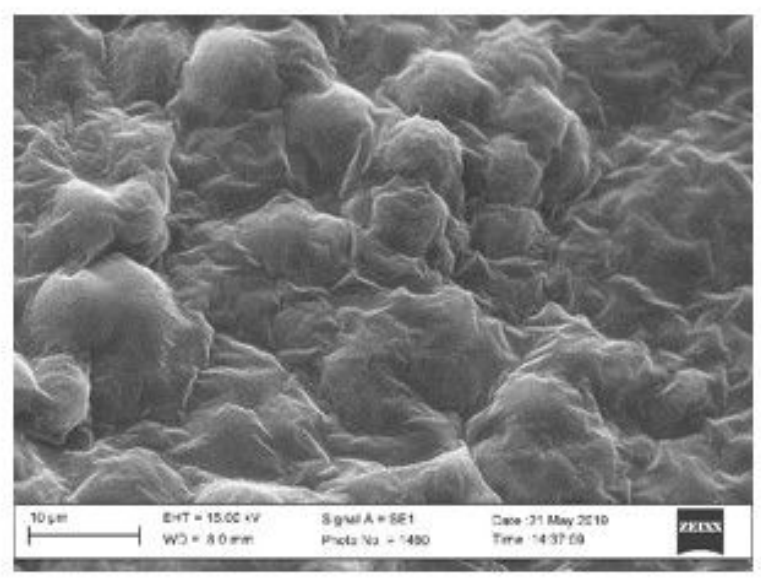

B

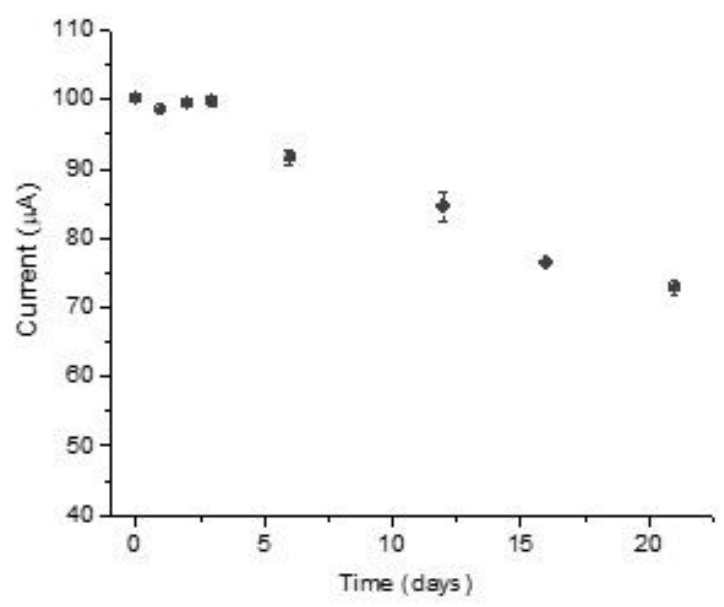

\section{Figure 5}

A) SEM analysis of the paper-SPEs with immobilised CC125 C. reinhardtii. B) Storage stability expressed as current signals of algae-paper-SPE sensors stored at $25^{\circ} \mathrm{C}$ under light illumination at $50 \mu \mathrm{mol}$ photons $m-2 \mathrm{~s}-1(n=3)$.

A

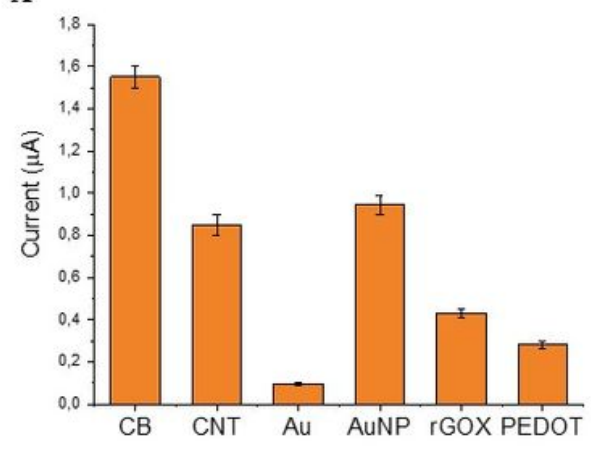

B

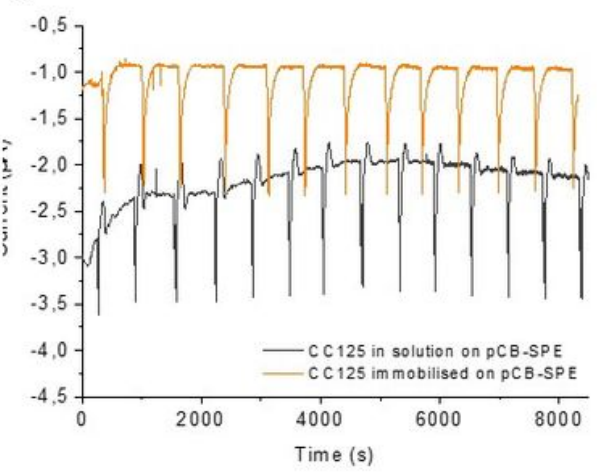

C

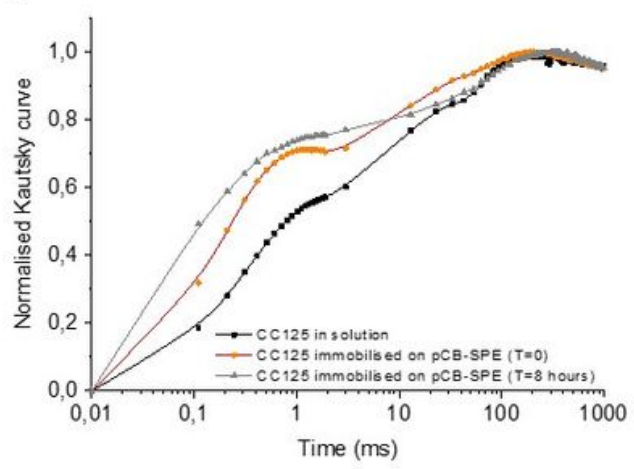

\section{Figure 6}

A) Current signal from oxygen evolution of CC125 C. reinhardtii whole cells immobilised on paper-based screen-printed electrodes modified with different (nano)materials. Working stability of C. reinhardtii immobilised on pCB-SPEs evaluated by amperometric (B) and fluorescence (C) analysis. Applied potential $-0.6 \mathrm{~V}$, interval analysis time $0.5 \mathrm{~s}$, repeated cycles of 10 min dark and $30 \mathrm{~s}$ light $(350 \mu \mathrm{mol}$ photons $\mathrm{m}-2 \mathrm{~s}-1)(\mathrm{n}=3)$. 
A

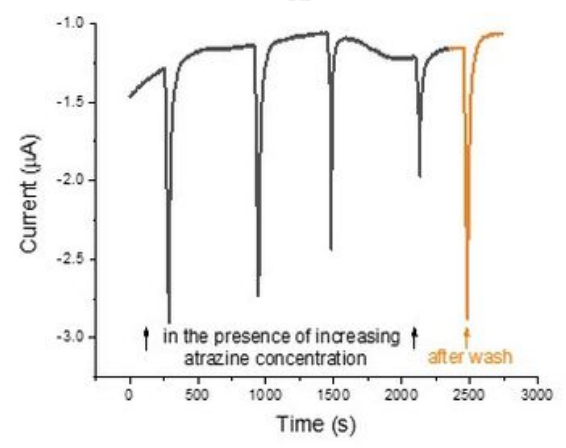

D

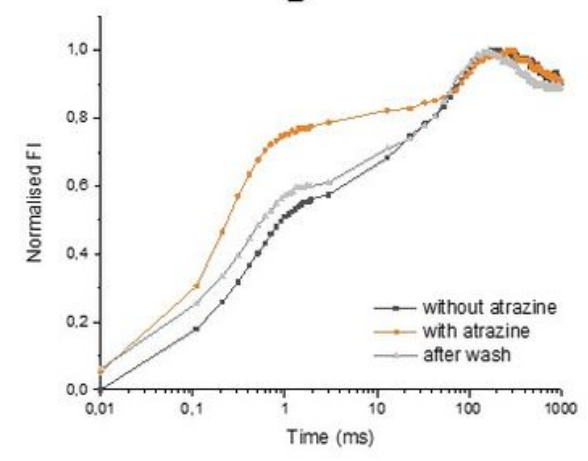

B

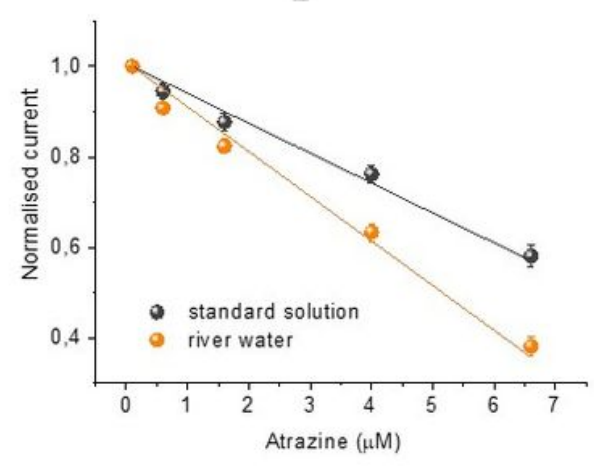

E

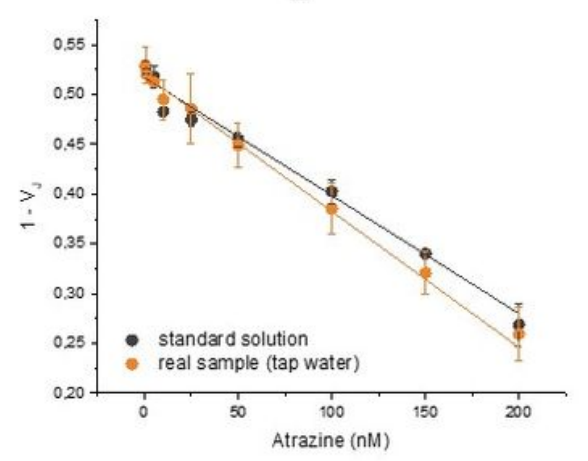

C

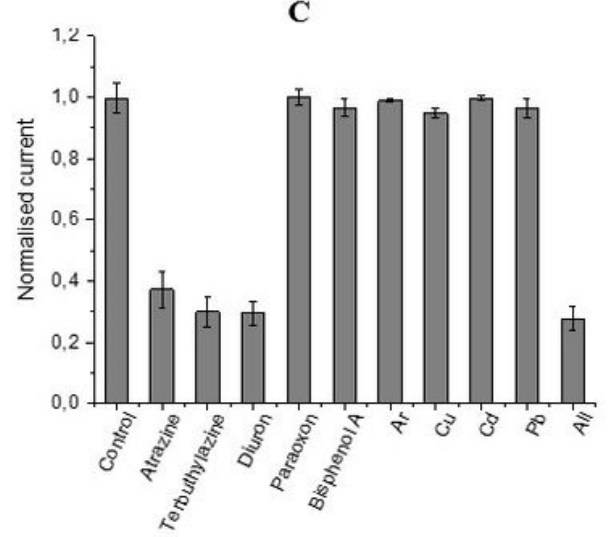

F

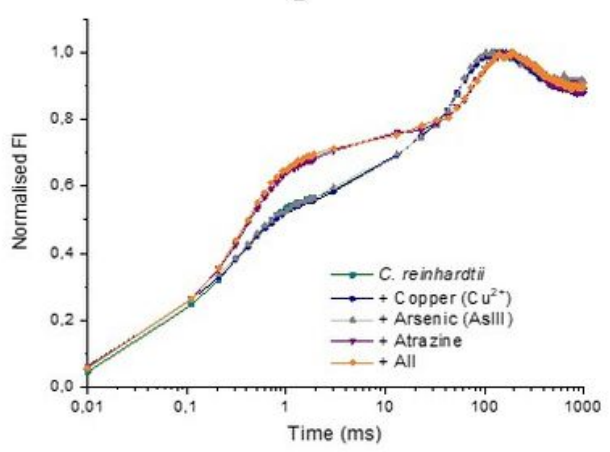

Figure 7

CC125 C. reinhardtii reversibility tests by amperometric (A) and fluorescence (D) analysis. Matrix effect by amperometric (B) and fluorescence (E) analysis. Study of the interferents by amperometric (C) and fluorescence $(F)$ analysis. Applied potential $-0.6 \mathrm{~V}$, interval analysis time $0.5 \mathrm{~s}$, repeated cycles of $10 \mathrm{~min}$ dark and 30 s light $(350 \mu \mathrm{mol}$ photons $\mathrm{m}-2 \mathrm{~s}-1)(\mathrm{n}=3)$.

\section{Supplementary Files}

This is a list of supplementary files associated with this preprint. Click to download.

- FigureS1.docx

- Graphicalabstract.docx 